\title{
The Relationships between Ball Throwing Velocity and Physical-psychomotor Features for Talent Identification in Physical Education
}

\author{
Zeynep Inci Karadenizli \\ Faculty of Sport Sciences, Duzce University, Turkey
}

Copyright $(2016$ by authors, all rights reserved. Authors agree that this article remains permanently open access under the terms of the Creative Commons Attribution License 4.0 International License

\begin{abstract}
The aim of this study is to investigate the relationships between ball throwing velocity (BTV), and physical features and anaerobic power (AP) for talent identification in team handball players. Players (n: 54) at $21,91 \pm 4,94$ age, training experience $11,19 \pm 4,46$ years participated voluntarily to study. These players consist of 54 Turkish national team female players. Spearman Correlation analysis was used for statistical evaluation and significance level was accepted as $p<0.05$. All statistical analyses were applied in SPSS 17.0. AP was calculated with Lewis formula. Significant relationships were determined between body height $(\mathrm{r}=0.393 ; \mathrm{p}=, 003)$, body weight $(\mathrm{r}=0.397 ; \mathrm{p}=, 003)$, hand length $(r=0.391 ; \mathrm{p}=, 003)$, arm $\operatorname{span}(\mathrm{r}=0.462 ; \mathrm{p}=, 000)$ and BTV during the 3 -step running throw $(\mathrm{p}<0.05)$. There were no significant relationships between BTV and training experience, body mass index, vertical jump height, AP $(p>0.05)$. In conclusion, it was determined that body height, body weight, hand length and arm span influence BTV positively. It is suggested to coaches and physical education teachers that children who have great body height, hand size, and arm span should be considered during talent identification applies for team handball in school.
\end{abstract}

Keywords Physical Education, Talent Identification Anthropometry, Handball

\section{Introduction}

Talent identification means to the process of recognizing current participants with the potential to become elite players. Many coaches and physical education teachers believe that talent identification is a vital factor of their elite sports development programs [14].

Physical development with the body height, weight and volumetric upregulation also means the expected changes from body system on the functions. Psychomotor development includes sense organs, working of muscle and nervous system coordinately. Hereby physical and psychomotor development attributions lie at the heart of neuromuscular system attributions such as strength, speed, stamina. The child finds the opportunity to have better functioning organs and systems with physical education and sports. Therefore, schools provide wide range of opportunities in terms of physical education; when bodies develop, it is important to gain resistance, agility and some habits with sports. For this reason, it is stated that children attend physical education and sports activities more frequently [50].

Talent identification progression from youth to elite sport is more complex in team sports than in individual sports. Regarding height, body mass, and explosive power, handball players appear to be positioned between volleyball players and soccer and field hockey players [14]. For talent identification a limited number of studies have mentioned some of anthropometric, physical fitness of youth and adult female handball players [11,32,40]. Previous studies on handball show that psychomotor characteristics such as speed, strength and jumping abilities are dependent on the level of competition [2,14].

Throwing is considered as one of the most crucial technical skills in handball as it is a major determinant of all actions taken by the players [1]. Throwing in handball, refers to movements in transferring the strength to hands occurred during movements of body segments and ball catching and thus releasing the ball. Previous studies show that the ball throwing velocity is the main performance factor determining the throwing movement [2,3,4,47].

As a physical feature it was suggested that, if the hands are bigger, ball can be caught better $[23,33,34]$. Hand spread is an important physical feature in handball, as it is correlated with BTV, more than the other sizes $[23,34]$. Visnapuu and Jurimae [47] also stated that hand size and finger length are important for throwing accuracy. When investigating mechanically, when ball is released, extension in elbow joint and pronation in hand, cause moment arm to get longer. In this case, it is known that linear velocity of arm increases. 
For this reason, if arm is longer then it is a mechanical advantage, and it affects throwing positively and increase ball velocity. In some studies it was suggested that combination of long arm and great angular velocity of arm cause great linear ball velocity $[12,35]$. Debanne and Laffaye [36] have also stated that to increase ball velocity, coaches should focuse on shoulder internal rotation and elbow extansion.

An enhanced throwing velocity is thought of major importance for a successful play, giving an estimated advantage of $11 \%$ in women [2]. Previous studies in the three most common techniques of handball throwing analyzed as the standing, the 3-step running throw and the jump shot. Although ball throwing velocity during the 3-step running throw is the greater than the other techniques, there are limited investigations between this technique and physical and fitness parameters in female handball players $[2,3,4]$. It can be seen that previous studies were examined frequently about the jump shot because of most common shot $[5,6,7,8]$.

Critical factors in throwing are as follows a transfer of power from the lower to the upper body and then to the ball [9]. The greatest part of the total impulse is derived from the lower limbs [10]. Although the movement of standing throwing forms a wide kinetic chain, which begins with the foot-ground contact and lasts with ball release, it is the upper extremity that directs the movement and transfers the generated force to the ball. The mentioned movement and strength spread is from consecutive greater segments which have wider joint space to more small segments which have more narrow joint movements. In this way, throwing motion occurs from proximal segments that are heavy and slow to distal segments that are light and fast. When investigating the throwing as segmental, the distance that hand take, is much more than elbow joint and the distance that elbow take is more than shoulder joint. Due to this reason, movement speed of hand is greater than forearm or arm segments' movement speed [11].

In addition to these, the physical features of the handball players and throwing technique determine the resulting (absolute) force, velocity and acceleration generated by the body segments [12]. In an another study, suggest that timing of wristlet, elbow, and pelvis joints and maximal absolute linear speed are effective in the differences occurring in ball throwing velocity at the end of force using phase (in other words, the last moment before ball release) [13]. Therefore, the kinetic and kinematic data from the shoulder, elbow, wrist joints and arm, forearm, hand segments, which determine the position of the suspending arm affects ball throwing velocity.

It has also indicated that certain physical features are related to high-level handball performance. Strength, jumping abilities and maximal running speed have an impact on handball performance $[15,16,17]$. As talency of vertical jump, provides a great advantage while throwing or blocking in defence is one of the most important basic features. For sudden accelerations in game, changing directions, jumps, and effective throws athletes need high level of anaerobic power and capacity $[1,2,18,19]$

Anaerobic power is defined as working ability without oxygen when organism cannot uptake adequate oxygen but be able to continue to work during exercises. Handball consists of by repeated periods of intense anaerobic activity $[20,21]$. In short time and high velocity loads, the importance of anaerobic system and the connection between high performance in $\mathrm{TH}$ and anaerobic metabolism were stated [22].

On the other hand, it was determined that ball throwing velocity is connected with anthropometric characteristics $[12,23]$, movement technic, power and strength of upper and lower limb muscles [3,17], elbow extension, wrist flexion and maximal angular velocity of shoulder internal rotation $[4,24]$.

On the contrary, concerning throwing velocity in, handball there are few studies which examine the relation with handball specific anthropometric parameters and physical fitness characteristics $[2,23,25]$. Joris et al. [3] have stated that the ball throwing velocity is positively correlated to the arm circumference but not to the arm length in female handball players. In another study, it was determined that there was a significant relationship between arm span and hand width, but there was no significant relationship with body height [23].

It is clear that there is controversy in the conclusions when trying to identify the exact physical and psychomotor variables that the throwing velocity is associated to. It is still unknown whether these features are correlated to the ball throwing velocity. Therefore, the purpose of this study was to examine any possible correlation between the ball throwing velocity during the 3 -step running throw and physical features, and anaerobic power for talent identification in elite female Turkish handball players.

\section{Materials and Methods}

\subsection{Participants}

All voluntary handball players $(n=54)$ had mean 11 years of training experience and $21,91 \pm 4,94$ years old. Participants consist of Senior National $(n=18$, age: $26,39 \pm$ 5,23 yrs), U19 national ( $\mathrm{n}=18$, age: $17,44 \pm 0,62 \mathrm{yrs}$ ) and Super League ( $\mathrm{n}=18$, age: $21,89 \pm 2,47$ yrs) female Turkish handball players. Fifty-four adolescent and senior volunteer without any sports injuries in the last year and visual-sensory disorders were enrolled in the study.

\subsection{Procedures}

The players trained 5 times per week except their matches. Research was carried out with who did not get injured and have an operation in last 1 year. Under nineteen (U 19) national team players, their parents and trainers were informed that participation was voluntary.

All players $(n=54)$ informed consent were obtained after 
thorough explanation of the objectives and scope of this research, the procedures, risks and benefits of the study. The study was conducted according to the Declaration of Helsinki and the protocol was fully approved by the Ethics Committee of the University. None of the participants reported any injury at the time of testing.

\subsection{Measures Protocol}

University gym and lab were used for tests. First of all body height, body weight, hand length and arm span measurements were taken from participants.

Body height was measured using a portable stadiometer (SECA, Leicester, UK).

Body weight was measured to the nearest $0,1 \mathrm{~kg}$, using an electronic weight scale (HD-351 Tanita, Illinois, USA).

Hand length and arm span were measured with measured ruler and they were expressed in $\mathrm{cm}$. After participants put their hands on a flat surface, as fingers closed, the distance between the most distant point of middle finger and wristlet line were measured ruler. Lean back on the wall, arms are open laterally and parallel to the ground, the distance between right and left middle fingertips were measured.

In addition, body mass index (BMI) was calculated as the quotient of body mass $(\mathrm{kg})$ to height squared $\left(\mathrm{m}^{2}\right)$.

For vertical jump and ball velocity tests will be carried out at same day. Each participant was allowed 20-minutes warm-up, including general and shoulder specific mobility and streching exercises. 3 minute rest was given between tests.

Countermovement jump (CMJ) test was chosen in recent study as previous research has indicated that strength, jumping abilities and maximal running speed have an impact on handball performance $[17,28]$. Height of each jump was estimated using the Ergojump (Bosco System, Globus, Italy). Participants were asked to jump an upward with double feet vertically without an obligation to bend knees, and their hands are on waist. After 1 minute resting time, each participant performed three trials upward vertically with maximum power. The best of three trial was recorded and expressed in $\mathrm{cm}$. CMJ protocols have been previously described [29].

Anaerobic Power (AP) was calculated by formula; AP: $[\sqrt{ } 4.9 \times$ body weight $\times \sqrt{D}](D=$ jump altitude). It is stated that top elite adolescent male handball players can enhance jump ability and absolute leg power by undertaking an 8 -week biweekly in season program of plyometric training involving exercises for lower limbs [26]. In fact, the jump rope motion requires a consecutive and syncronized use of both upper and lower body with a high degree of coordination and rhythmicity [27].

Ball throwing velocity (BTV) was recorded with a radar gun (Sports Radar 3300, Electronics Inc, USA). Measurements were carried out with a radar settled 1,5 m behind the ball, in line with goal and ball. A standard handball ball no.2 (54-56 cm perimeter, 325-375 g) was used in the throw velocity tests. Target frames $(60 \times 60 \mathrm{~cm})$ were settled at upper corners of the goal. The participants were instructed to throw with maximum of three steps prior to throwing the ball at the highest possible speed, onto a target at $9 \mathrm{~m}$ distance from the goal. The contra-lateral leg of the throwing hand was steadily planted on the ground. With the purpose of motivating the players, they were informed about the velocity value obtained immediately after each throw. The procedure was the following [2]: each participant performed three trials the 3-step running throw with a 10-15 sec pause between them. The best score (highest speed of the ball) was evaluated and expressed in $\mathrm{kmh}$. The coaches supervised the entire throwing test to ensure that the subjects were using the right handball technique.

Testing periods were scheduled minimum 24 hours after a handball training/match to minimize the effect of fatique.

\subsection{Statistical Analysis}

Normal distribution examinations of data with Shapiro-Wilk test and Variance homogeneity examinations were carried out with Levene test. Descriptive statistics (mean, standard deviation, minimum and maximum) were used. As data have non-parametrical quality they were assessed by Spearman correlation test. All statistical analyses were conducted in Statistical Package for the Social Science (SPSS) (Version 17.0 Software for Windows). Significance level was accepted as $\mathrm{p}<0.05$.

\section{Results}

The results of this study are presented in the following two tables. Descriptive analysis of the parameters measured; mean BTV during the 3-step running throw was determined as $76.83 \pm 8.96 \mathrm{kmh}$. Mean training experience was found as $11,19 \pm 4,46$ yrs. Values for mean body height, weight and BMI were found as $171,74 \pm 5,55 \mathrm{~cm}, 65,20 \pm 6,66 \mathrm{~kg}, 21,97$ $\pm 1,99$, respectively. Mean hand length and arm span were found as 18,94 $\pm 1,07 \mathrm{~cm}, 169,85 \pm 7,94 \mathrm{~cm}$, respectively. Mean CMJ and AP were found as 32,33 $\pm 6,63 \mathrm{~cm}, 105,93 \pm$ $21,06 \mathrm{~kg} . \mathrm{m} / \mathrm{s}$, respectively. These descriptive data are presented in Table 1.

Table 1. Descriptive data of the parameters measured

\begin{tabular}{|c|c|}
\hline $\begin{array}{c}\mathrm{n}=54 \\
\text { Parameters }\end{array}$ & Mean \pm SD \\
\hline Age (year) & $21.91 \pm 4.94$ \\
\hline Training experience $($ year $)$ & $11.19 \pm 4.46$ \\
\hline Body height $(\mathrm{cm})$ & $171.74 \pm 5.55$ \\
\hline Body weight $(\mathrm{kg})$ & $65.20 \pm 6.66$ \\
\hline BMI $\left(\mathrm{kg} / \mathrm{cm}^{2}\right)$ & $21.97 \pm 1.99$ \\
\hline Hand length $(\mathrm{cm})$ & $18.94 \pm 1.07$ \\
\hline Arm span $(\mathrm{cm})$ & $169.85 \pm 7.94$ \\
\hline CMJ $(\mathrm{cm})$ & $32.33 \pm 6.63$ \\
\hline AP $(\mathrm{kg} . \mathrm{m} / \mathrm{s})$ & $105.93 \pm 21.06$ \\
\hline BTV $(\mathrm{kmh})$ & $76.83 \pm 8.96$ \\
\hline
\end{tabular}


Table 2. Correlations between the ball throwing velocity and values of test parameters

\begin{tabular}{|c|c|l|}
\hline $\begin{array}{c}\mathrm{n}=54 \\
\text { Parameters }\end{array}$ & $\mathrm{r}$ & $\mathrm{p}$ \\
\hline Training experience & .173 & .212 \\
\hline Body height & .393 & $.003^{*}$ \\
\hline Body weight & .397 & $.003^{*}$ \\
\hline BMI & .185 & .180 \\
\hline Hand length & .391 & $.003^{*}$ \\
\hline Arm span & .462 & $.000^{*}$ \\
\hline CMJ & .132 & .342 \\
\hline AP & .146 & .293 \\
\hline
\end{tabular}

$* \mathrm{p} \leq 0.05$

Spearman Correlation analysis showed significant relations $(\mathrm{p}<0.05)$ between BTV during the 3-step running throw and body height $(\mathrm{r}=0.393 ; \mathrm{p}=0.003)$, weight $(\mathrm{r}=$ $0.397 ; \mathrm{p}=0.003)$, hand length $(\mathrm{r}=0.391 ; \mathrm{p}=0.003)$ and arm $\operatorname{span}(\mathrm{r}=0.462 ; \mathrm{p}=0.000)$. There was no significant relation between BTV and training experience $(r=0.173 ; \mathrm{p}=0.212)$, BMI $(r=0.185 ; \mathrm{p}=0.180), \mathrm{CMJ}(\mathrm{r}=0.132 ; \mathrm{p}=0.342)$ and AP $(r=0.146 ; p=0.293)(p>0.05)$. The Spearman Correlation analysis results are presented in Table 2 .

\section{Discussion}

The aim of this study was to search correlation between ball throwing velocity (BTV) and physical-psychomotor features for talent identification in physical education.

In the current study, mean body height as $171,74 \pm 5,55 \mathrm{~cm}$, body weight as $65,20 \pm 6,60 \mathrm{~kg}$; BMI as $21,97 \pm 1,99$; hand length as $18,94 \pm 1,07 \mathrm{~cm}$, arm span as $169,85 \pm 7,94 \mathrm{~cm}$ were found in elite female handball players (aged $=21,91 \pm 4,94$ yrs). It was reported that mean body height was $176,0 \pm 6,5$ $\mathrm{cm}$; body mass was $72,5 \pm 8,3 \mathrm{~kg}$ and BMI was $23,4 \pm 2,3$ in elite female handball players (aged $=24,0 \pm 3,5$ yrs) [30]. Another study was reported that mean body height was $169,2 \pm 6,04 \mathrm{~cm}$; body mass was $67,0 \pm 7,91 \mathrm{~kg}$ and BMI was $23,4 \pm 5,33$ in elite female handball players (aged $=26,4 \pm 5,77$ yrs) [31]. It was also reported that body height was $170,9 \pm 6,2 \mathrm{~cm}$; body mass $69 \pm 8,7 \mathrm{~kg}$ in female experienced handball players (aged $=22,2 \pm 2,6 \mathrm{yrs}$ ) [32]. In the current study, mean BTV during the 3-step running throw was found as $76.83 \pm 8.96 \mathrm{kmh}$. Karadenizli et al. [11] have concluded that in the same technique to the goal with signed target BTV was $65.92 \pm 11.11 \mathrm{kmh}$ and without target it was $70,25 \pm 11.46$ $\mathrm{kmh}$ in senior Turkish National female players (aged= $22,92 \pm 2,43 \mathrm{yrs}$ ). Previous studies examined with nearly same ages in female handball players at the same technique show that BTV was found as $61,92 \mathrm{kmh}$ [3], as $69,12 \mathrm{kmh}$ [32], and as $75,96 \mathrm{kmh}$ in [2]. It is seen that result found current study greater than the previos studies.

In the current study, significant relations were found between BTV and body height ( $r=0.393 ; \mathrm{p}=0.003)$, body weight $(r=0.397 ; p=0.003)$, hand lenght $(r=0.391 ; p=$
$0.003)$ and arm $\operatorname{span}(\mathrm{r}=0.462 ; \mathrm{p}=0.000)(\mathrm{p}<0.05)$.

In addition, handball players whose throwing have great ball velocity, have great arm span and this case is related to their body height $[2,12,14]$. Tall players seem to perform better than short ones, as it is generally accepted that body height positively affects on all of important skills in handball [24,37]. Nikolaidis and Ingebrigtsen [38] have also reported two main characteristics (stature and ability to perform continuous jumping) that discriminate players according to their team ranking. In addition, they stated both physiological and physical characteristics can be useful for discriminating between elite male handball players. Lidor et al. [14] also stated that height is an important variable in handball.

Skoufas et al. [23] have determined that there is a significant positive relationship between BTV and body weight, arm span, hand span and width. Debanne and Laffaye [25] have concluded that there is a significant positive correlation between BTV and general anthropometric parameters. Among these factors, body mass appears to have the strongest correlation with BTV. Van den Tillaar and Ettema [32] have also stated BTV and strength are strongly and positive related to body height, body mass and fat-free body mass for female and male combined. It is seen that the results of the current study support to the previous studies. In addition, it also states that the ratio (arm span / body height) for elite athletes should be 1.05-1.06 $[23,39]$. In the current study, this ratio was found as 0.98 .

In the current study, mean body weight was found as $65,20 \pm 6,60 \mathrm{~kg}$. Although this value is lower than results of previous studies $[30,31,32]$ which had been examined with female handball players at the same ages, significant relation was found between BTV and body weight in the current study $(\mathrm{p}<0.05)$. This result could be explained by the greater muscle mass of heavier players. On the other hand, in the current study mean BMI was found as $21,97 \pm 1,99$. Although this value is better than results of previous studies [30,31] which had been examined with female handball players at the same ages, significant relation was not found between BTV and body weight in the current study ( $p>0.05)$.

Apart from these results, it was seen that there could be significant differences in ball velocity of elite and non-elite athletes' ball velocity values [23]. In the current study, all players had an elite players and they had mean 11 years of training experience but, significant relation was not found between BTV and age, and training experience ( $p>0.05)$.

In an another result in current study, mean CMJ was determined as $32,33 \pm 6,63 \mathrm{~cm}$, and mean AP was determined as $105.93 \pm 21.06 \mathrm{~kg} . \mathrm{m} / \mathrm{s}$. Savucu et al. [40] have concluded anaerobic power as $114,16 \pm 6,26 \mathrm{~kg} . \mathrm{m} / \mathrm{s}$ in female handball players (aged $=20,75 \pm 2,70 \mathrm{yrs}$ ). Handball players perform throws in along and vertical jump in an effort to overcome the opponent's defence block [41]. It was stated that there is positive significant relationship between CMJ and leg strength, leg strength and AP $[42,43,44]$. In addition, in studies it is stated that AP of handball players are quite high $[19,20,21,22]$. 
In many studies related to handball, it was seen that, there is a high relation between lower extremity explosive power and ball velocity [3,17]. In a study Granados et al. [2] have performed with elite and amateur female handball players, they determined that there are significant relations between $\mathrm{AP}$ and BTV. It was stated that altitude of vertical jump was significantly influenced by leg strength $[42,44]$. Furthermore, the association observed between lower extremity muscle power and a 3-step running throw has also been found in elite male handball players and can be explained by the involvement of larger leg muscles during handball throwing [3].

Cherif et al. [15] have also proved that anaerobic performances were increased in-season by a specific combined training program. Improvements in physical qualities were also possible during 12 week period. In addition, it was indicated that it was not appropriate to directly link physical performance to a handball team's performance. Opposite to these results, significant correlations were not found between BTV and CMJ and AP in the current study ( $>0.05$ ). It is thought that few studies have been examined about these correlations. In addition, strength and flexibility of lower limb muscles measurements were not conducted in the current study. It is thought that if these features were measured too, the relationship that was not significant between AP and BTV could have been explained better.

On the other hand, the "relative age effect" is an issue that needs to be addressed because it is vital for young children to have equal opportunities for participation and development in their best potential within sport [45]. It is stated that some physical features can be unreliable predictors of a future potential performance because of their high variability during puberty [46].

On the contrary, hand dimensions may influence handgrip strength and the athletes have biomechanical advantages [47]. Clerke et al. [48] have proved that anthropometric variables, such as height, weight, hand length, and hand width are positively associated with grip strength in healthy adults. Jayakumar et al. [49] have also stated that hand width and length show significant impact on griping the ball in handball. In previous studies it was determined that handball players had long arms, long legs and they were tall with broad-shouldered body and they had above mean body weight $[22,37,39,41]$. These studies are in agreement with current study.

\section{Conclusions}

This study shows that body height, body weight, hand length and arm span positively influence to BTV during the 3 -step running throw in team handball. There are significant relationships that were determined between these physical features and BTV. The results of current study show that these characteristics which was mentioned above are also important an advantage in handball. For this reason, it is suggested that coaches and physical education teachers should focus on children who have great body height, size of hand and arm span while talent identification applies in school.

\section{REFERENCES}

[1] Zapartidis I., Skoufas D., Vareltzis I., Christodoulidis T., Toganidis T., \& Kororos P. (2009a). Factors influencing ball throwing velocity in young female handball players. Open Sport Medicine Journal, 3, 39-43.

[2] Granados C., Izquierdo M., Ibanez J., Bonnabau H., \& Gorostiaga, E. M. (2007). Differences in physical fitness and throwing velocity among elite and amateur female handball players. Int J Sports Medicine, 28, 860-867.

[3] Joris H., Van Muijen A. E, Van Ingen Schenau G. J., \& Kemper H. C. G. (1985). Force, velocity and energy flow during the overarm throw in female handball players. Journal of Biomechanics, 18(6), 409-414.

[4] Van den Tillaar R., \& Ettema G. (2007). A three-dimensional analysis of overarm throwing in experinced handball players. Journal of Applied Biomechanics, 23, 12-19.

[5] Meric B., Aydin M., Colak T., Ozbek A., \& Bulgan C. (2009). $3 \mathrm{D}$ kinematic analysis of overarm movements for different sports. Kinesiology, 41(1), 105-111.

[6] Plummer H., \& Oliver G. D. (2016). The effects of localised fatique on upper extremity jump shot kinematics and kinetics in handball. Journal of Sports Sciences, doi: 10.1080/02640414.2016.1160143

[7] Wagner H., Buchecker M., von Duvillard S. P., \& Muller E. (2010). Kinematic description of elite vs. low level players in team-handball jump throw. Journal of Sports Science \& Medicine, 9(1), 15-23.

[8] Wagner H., Pfusterschmied J., von Duvillard S. P., \& Muller E. (2011). Performance and kinematics of various throwing techniques in team-handball. Journal of Sports Science \& Medicine, 10, 73-80.

[9] Litwiler D., \& Hamm J.(1973). Overload: Effect on throwing velocity and accuracy. Athletic Journal, 53, 64-65.

[10] Van den Tillaar R. (2004). Effect of different training programs on the velocity of overarm throwing: a brief review. Journal of Strength and Conditioning Research, 18, 388-396.

[11] Karadenizli I., Inal S., Meric B., Aydin M., \& Bulgan C. (2014). Accuracy and velocity of the elite female Turkish handball players. International Journal of Sports Science, 4(1), 21-26.

[12] Bayios I., Anastasopolou E., \& Sioudris, Boudolos, K. (2001). Relationship between isokinetic strength of the internal and external shoulder rotators and ball velocity in team handball. The Journal of Sports Medicine and Physical Fitness, 41, 229-235.

[13] Van den Tillaar R., \& Ettema G. (2003). Instructions emphasizing velocity, accuracy or both in performance and kinematics of overarm throwing by experinced team handball 
players. Percept Mot. Skills, 97(3 Pt 1), 731-742.

[14] Lidor R., Falk B., Arnon M., Cohen Y., Segal G., \& Lander Y. (2005). Measurement of talent in team handball: the questionable use of motor and physical tests. Journal of Strength and Conditioning Research, 19, 318-325.

[15] Cherif M., Mohammed S., Chaatani S., Nejlaoui O., Gomri D., \& Abdallah A. (2012). The effect of a combined high-intensity plyometric and speed training program on the running and jumping ability of male handball players. Asian Journal of Sports Medicine, 3(1), 21-28.

[16] Jensen J., Jacobsen S. T., Hetlan S., \& Tveit P. (1997). Effect of combined endurance, strength and sprint training on maximal oxygen uptake, 1sometric strength and sprint performance in female elite handball players during a season. International Journal of Sports Medicine, 18(5), 354-358.

[17] Marques M. C., \& Gonzales-Badillo J. J. (2006). In-season resistance training and detraining in professional team handball players. Journal of Strength and Conditioning Research, 20(3), 563-571.

[18] Izquierdo M., Hakkinen K., Gonzales-Badillo J. J., Ibanez J., \& Gorostiaga E. M. (2002). Effects of long term training specificity on maximal strength and power of the upper and lower extremities in athletes from different sports. Eur J. Appl Physiol, 87, 264-271.

[19] Norkowski H. (2002). Anaerobic power of handball players representing various sport levels. Journal of Human Kinetics, $7,43-50$.

[20] Kruger K., Pilat C., Ueckert K., French T., \& Mooren F. C. (2014). Physical performance profile of handball players is related to playing position and playing class. Journal of Strength and Conditioning Research, 28, 117-125.

[21] Manchado C., Tortosa-Martinez J., Vila H., Ferragut C., \& Platen P. (2013). Performance factors in women's team handball: physical and physiological aspects- a rewiev. Journal of Strength and Conditioning Research, 27, 1708-1719.

[22] Povoas S. C., Seabra A. F., Ascensao A. A., Magalhaes J., Soares J. M., \& Rebelo A. N. (2012). Physical and physiological demands of elite team handball. Journal of Strength and Conditioning Research, 26, 3365-3375.

[23] Skoufas D., Kotzamanidis C., Hatzikotoylos K., Bebetsos G., \& Patikas D. (2003). The relationship between the anthropometric variables and the throwing performance in handball. Journal of Human Movement Studies, 45, 469-484.

[24] Van den Tillaar R., \& Ettema G. (2004a). A force-velocity relationship and coordination patterns in overarm throwing. Journal of Sports Science and Medicine, 3, 211-219.

[25] Debane T., \& Laffaye G. (2011). Predicting the throwing velocity of the ball in handball with anthropometric variables and isotonic tests. Journal of Sports Sciences, 29(7), 705-713.

[26] Hermassi S., Gabbett T. J., Ingebrigtsen J., Van den Tillaar R., Chelly M. S., \& Chamari K. (2014). Effects of a short-term in-season plyometric training program on repeated-sprint ability, leg power and jump performance of elite handball players, International Journal of Sports \& Coaching, 9(5), $1205-1216$.

[27] Bobbio T., Gabbard C., \& Cacola, P. (2009). Interlimb coordination: An important facet of gross-motor ability. Early Chilhooh Research \& Practice, 11, n2.

[28] Jensen J., Jacobsen S. T., Hetlan S., \& Tveit P. (1997). Effect of combined endurance, strength and sprint training on maximal oxygen uptake, 1sometric strength and sprint performance in female elite handball players during a season. International Journal of Sports Medicine, 18(5), 354-358.

[29] Markovic G., Dizdar D., Jukic I,. \& Cardinale M. (2004). Reliability and factorial validity of squat and countermovement jump tests. The Journal of Strength and Conditioning Research, 18(3), 551-555.

[30] Mala L., Maly T., Zahalka F., Bunc V., Kaplan A. Jebavy R., \& Tuma M. (2015). Body composition of elite players in five different sport games. Journal of Human Kinetics, 45, 207-215.

[31] Milanese C., Piscitelli F., Lampis C., \& Zancanaro C. (2012). Effect of a competitive season on anthropometry and three-compartment body composition in female handball players. Biol. Sport, 29, 199-204.

[32] Van den Tillaar R., \& Ettema G. (2004b). Effect of body size and gender in overarm throwing performance. Eur J Appl Physiol, 91(4), 413-418.

[33] Burton A. W., Greer N. L., \& Wiese D. M. (1993). Variation in grasping and throwing patterns as a function of ball size. Pediatr Exerc Sci., 5, 25-41.

[34] Zapartidis I., Vareltzis I., Gouvali M., \& Kororos P. (2009b). Physical fitness and anthropometric characteristics in different levels of young team handball players. The Open Sports Sci J., 2, 22-28.

[35] Fleising G. S., Barrentine S. W., Zheng N., Escamilla R F., \& Andrews J. R. (1999). Kinematic and kinetic comparison of baseball pitching among various levels of development. Journal of Biomechanics, 32, 1371-1375.

[36] Debane T., \& Laffaye G. (2013). Coaches' beliefs and knowledge: Training programs used by French professional coaches to increase ball-throwing velocity in elite handball players. International Journal of Sports \& Coaching, 8(3), 557-569.

[37] Bayios I. A., Bergeles N. K., Apostolidis N. G., Noutsos K. S., \& Koskolou M. D. (2006). Anthropometric, body composition and somatotype differences of Greek elite female basketball, volleyball and TH players. J Sports Med. Phys. Fitness, 46, 271-280.

[38] Nikolaidis P. T., \& Ingebrigtsen J. (2013). Physical and physiological characteristics of elite male handball players from teams with a different ranking. Journal of Human Kinetics, 38, 115-124.

[39] Hatzimanouil D., \& Oxizoglou N. (2004). Evaluation of the morfological characteristics and motor skills in the national junior handball teams of Greece and Yugoslavia. J Hum Mov Stud., 46, 125-40.

[40] Savucu Y., Erdemir I., Akan I., \& Canikli A. (2006). Elit bayan basketbol ve bayan hentbol oyuncularinin fiziksel uygunluk parametrelerinin karsilastirilmasi. Spormetre Beden Egitimi ve Spor Bilimleri Dergisi. 4(3), 111-116.

[41] Galal El-Din H., Zapartidis I., \& Ibrahim H. A. (2011). Comparative study between talented young Greek and 
German handball players in some physical and anthropometric characteristics. Biol. Sport, 28, 245-248.

[42] Alemdaroglu U. (2012). The relationship between muscle strength, anaerobic performance, agility, sprint ability and vertical jump performance in professional basketball players. Journal of Human Kinetics, 31, 99-106.

[43] Arslan C. (2005). Relationship between the 30-second wingate test and characteristics of isometric and explosive leg strength in young subjects. Journal of Strength and Conditioning Research, 19(3), 658-666.

[44] Mayhew J., Hancock K., Rollison L., Ball T., \& Bowen J. (2001). Contributions of Strength and body composition to the gender difference in anaerobic power. Journal of Sport Medicine and Physical Fitness, 41, 33-38.

[45] Andronikos G., Elumaro A.I., Westbuy T., \& Martindale R. J. J. (2016). Relative age effect: implications for effective practice. Journal of Sports Sciences, 34(12), 1124-1131.

[46] Pearson D. T., Naughton G. A., \& Torode M. (2006). Predictability of physiological testing and the role of maturation in talent identification for adolescent team sports. J Sci Med Sports, 9, 277-287.

[47] Visnapuu M., \& Jurimae T. (2007). Handgrip strength and hand dimensions in young TH and basketball players. Journal of Strength and Conditioning Research, 21(3), 923-929.

[48] Clerke A. M., Clerke J. P., \& Adams R. D. (2005). Effects of hand shape on maximal isometric grip strength and its reliability in teenagers. Journal of Hand Therapy, 18(1), 19-29.

[49] Jayakumar C., Rameshkanan S., \& Chittibabu C. (2013). Analysis of selected hand anthropometric measurements among south west zone inter university male handball players. International Journal of Physical Education, Fitness and Sports, 2(4), 12-16.

[50] Bar M., Menzure S.B. , \& Hergüner G. (2016). Problems Encountered by Religious Vocational Secondary School and Other Secondary School Students in Physical Education and Sports Activities. Universal Journal of Educational Research 4(4), 664-674. 